\title{
Effects of stage-matched repeated individual behavioural counselling session (RIBCS) as an intervention for decreased and stopping smoking
}

\author{
Gopal Chawla1, Amrit Pal Kansal' ${ }^{1}$, Kunal Deokar ${ }^{2}$, Nupur Abrol ${ }^{3}$, Vishal Chopra ${ }^{1}$, Pranav Ish ${ }^{4}$, \\ Vinod Sharma ${ }^{5}$, Naresh Kumar ${ }^{1}$, Komaldeep Bhatti ${ }^{1}$ \\ ${ }^{1}$ Government Medical College and Hospital, Patiala, Punjab; ${ }^{2}$ Government Medical College, Nagpur, Maharashtra; \\ ${ }^{3}$ All India Institute of Medical Sciences, New Delhi; ${ }^{4}$ Vardhaman Mahavir Medical College and Safdarjung Hospital, \\ New Delhi; ${ }^{5}$ Sawai Man Singh Medical College, Jaipur, Rajasthan, India
}

\begin{abstract}
We aimed to evaluate the effects of stage-matched repeated individual behavioural counselling (RIBCS) on the basis of the transtheoretical model (TTM) as an intervention to reduce and stop smoking. This study was conducted over a period of one year where all smokers presenting to a chest clinic in a tertiary centre were enrolled, each was classified on the basis of stage of readiness to change and underwent repeated counselling for a period of six months and each session was preceded and succeeded with filling of Fagerstorm test for nicotine dependence. Over the period of a year, 207 patients participated in this study, the mean age was $50.74 \pm 14.74$ years; mean duration of tobacco use was $29.43 \pm 14.72$ years; $64.3 \%$ were illiterate, $11.6 \%$ primary education, $14.1 \%$ were matric and while $10.1 \%$ were graduate. About $73 \%$ of smokers
\end{abstract}

Correspondence: Dr. Kunal Deokar, Government Medical College, Nagpur, Maharashtra, India. E-mail: dkunal@live.in

Contributions: GC, APK, VC, KD, PI, concept of the study; GC, APK, VC, KD, PI, KB, study design; KD, VS, NK, literature search; GP, VS, clinical studies; GC, APK, VS, experimental studies; GC, APK, NA, NK, KB, data acquisition and analysis; GC, NK, statistical analysis; GC, KD, research guarantor. All the authors have read and approved the final version of the manuscript and agreed to be accountable for all aspects of the work.

Conflict of interest: The authors declare that they have no competing interests, and all authors confirm accuracy.

Informed consent: Obtained from all enrolled patients.

Key words: Smoking cessation, Smoking, Psychosocial problems, Behavioural therapy.

Received for publication: 3 December 2019.

Accepted for publication: 18 February 2020.

${ }^{\text {CC }}$ Copyright: the Author(s), 2020

Licensee PAGEPress, Italy

Monaldi Archives for Chest Disease 2020; 90:1208

doi: 10.4081/monaldi.2020.1208

This article is distributed under the terms of the Creative Commons Attribution Noncommercial License (by-nc 4.0) which permits any noncommercial use, distribution, and reproduction in any medium, provided the original author(s) and source are credited. reported high level of nicotine dependence (FTND score $>5 / 10$ ). In the present study mean dependence score was $6.0 \pm 1.96 ; 44$ $(21.3 \%)$ were in pre-contemplation stage, $93(44.9 \%)$ were in contemplation, $57(27.5 \%)$ were in preparation and $13(6.3 \%)$ were in action. The point prevalence excellence rate in follow up-I was $15 \%$, follow up-II was $35.3 \%$ and follow up-III was $61.9 \%$ which was statistically significant. When we took both abstinence and reduction in smoking behaviour as one, p-value was $<0.05$. The point prevalence of abstinence rate (questionnaire validated) 1 month to 6 months was almost 4 times. Our intervention (RIBCS) succeeded in increasing the abstinence rates during the study period among smokers with a lower motivation to quit (pre-contemplators and contemplators) as well as those ready to quit (preparators). This is significant because of most existing smoking-cessation interventions target only motivated smokers, with few having a positive effect in smokers with a lower motivation to quit.

\section{Introduction}

Smoking is one of the major causes of death worldwide and the most preventable risk factor of death. Smoking kills almost 9 million people every year in our country, and unless corrective action is taken soon that number will increase to 1 million smokingrelated deaths annually by 2010 and beyond [1]. It is the most important modifiable risk factor for coronary artery disease, chronic obstructive pulmonary disease, hypertension and carcinomas originating in the nasopharynx, bronchus, oesophagus, etc. [2].

Cessation can significantly reduce the risk of suffering from smoking-related diseases. Smoking cessation therapies that have proven effective, range from simple counselling to intensive interventions using the medication, though an integrated approach comprising counselling and pharmacological support is superior. Smoking cessation counselling has shown limited efficacy alone [3]. Smoking cessation is known to produce an immediate decline in the blood carbon monoxide levels, normalization of pulse rate, blood pressure, and restoration of sense of a taste and smell [4]. Risks for lung cancer, coronary heart disease, and chronic obstructive pulmonary disease are also markedly reduced by smoking cessation [5].

Studies have shown that counselling with a health professional is an effective method to help smokers quit [6-8]. A survey of smokers in the United States found that if given a choice, they would prefer to receive smoking cessation counselling from a health professional. Cessation rates of 10 to $20 \%$ have been found after patients received professional advice and appropriate assistance from their physicians [9]. 
Because of the extremely addictive nature of cigarette smoking which is often attributed to nicotine dependence. Although psychological components, habituation and genetic influences also play an important part in this addiction. Patients should not become discouraged if initial attempts to stop are unsuccessful. The health care professional are well aware of these problems and are better equipped to handle it. Therefore repeated attempts are worth the effort, not only from the perspective of the individual smoker but also from that of their families and society at large as well. Despite the higher prevalence of smoking, few studies have been conducted on smoking cessation as it is not a core research field in many disciplines.

\section{Objectives}

The purpose of this study was to evaluate the effects of stagematched repeated individual behavioural counselling (RIBCS) as an intervention to reduce and stop smoking and to evaluate various factors like literacy, loss of motivation and nicotine dependence which are associated with it.

\section{Materials and Methods}

\section{Study design}

A prospective cohort study where all patients attending a Chest Clinic in 1 year and were smokers were enrolled.

\section{Participants}

Current smokers among outpatients presenting to Chest Clinic, who provided informed consent and who were not willing for pharmacological therapy were enrolled in this study. Current smokers were defined as those who have smoked cigarette, bidi (hand-rolled tobacco products smoked in south Asia) or hukkah (glass based waterpipe used for smoking) at least once in the past 30 days, had smoked at least 100 times in their lifetime, smoked for at least 1 year, smoked at their current rate (i.e., daily or non-daily) for at least 6 months, and had not participated in any smoking cessation treatment in the past 30 days [10-12].

Subjects with experience of smoking cessation medicine, previously enrolled in any smoking cessation programme, not willing to follow up for 6 months, cognitive impairment and not giving consent were excluded from the study. As we required new subjects where behavioural model can be applied and they can be regularly followed up.

\section{Methodology}

Demographic, socio economic data along with smoking history were noted. Patients mobile phone number along with contact number of their immediate relatives were noted to strengthen the follow up. Further, smokers were classified as per exposure level, based on smoking index criteria [13]. Each participant was further analysed for nicotine dependence according to Fagerström test for nicotine dependence. Fagerström test for nicotine dependence (FTND) measures the severity of dependence on a scale from 0 to
10 based on the patient's answers to a six-item questionnaire [14].

Each subject underwent repeated counselling for period of a 6 months and each session was preceded with filling of Fagerström Test for Nicotine dependence (FTND). Patients were advised to quit smoking in a clear and strong manner. It is generally accepted that the motivation to quit is one of the most significant factors associated with smoking cessation followed by family support and literacy level. All participants were subjected to a pre-formed questionnaire and were divided into four categories according to their motivation to quit. They were assigned to various stages of smoking cessation according to health belief model into Precontemplation, contemplation, preparation and Action. Those who are in stage precontemplation and contemplation were considered one with lower motivation. Smokers in each category were assigned to the intervention which was repeated individualised counselling for smoking cessation (RIBCS).

The advice was at times personalised for the patient, highlighting his/her situation and the impact of smoking on children. Subsequently, the patients in the early stages of readiness to change (Stage 1-3) underwent counselling session, an approach based on cognitive behaviour therapy, focusing on the tobacco user and designed to help resolve the ambivalence related to tobacco use and change the behavioural stage [15]. Based on the motivational stage and presence of co morbidities, treatment modalities offered included behavioural counselling for all patients which was personalized according to need of the patient. Pre-contemplators and contemplators were urged to quit smoking where they were told about positive effects of smoking cessation along with negative effects of the continuance of smoking and effect of second hand smoke was stressed. While those in preparation stage were guided by setting quit date and personalized information on cognitive and behavioural strategies for quitting were provided.

At follow-up sessions, if they succeeded in quitting smoking, they were first congratulated and given badge saying "I QUIT SMOKING with the date", then questioned about withdrawal symptoms and the urge to smoke, and provided with the solutions to prevent relapse. Family member accompanying the person was guided to support them by encouraging them. At the latter part of the follow-up sessions they were told how continuing stopping smoking would change their lives by empowering them financially, physically, mentally and spiritually. If smokers relapsed, we discussed the reasons for their behaviour, and encouraged them to try to quit smoking again.

\section{Variables}

All patients who were smokers [12], were classified as mild, moderate and heavy on basis of smoking index [13]. Patient were defined as moderately dependent on nicotine if FTND score was more than or equal to $5[16,17]$. Various stages of health belief model such as Pre-contemplation, Contemplation, Preparation and Action were defined as standard as per trans theoretical model [14].

\section{Data measurement}

After individualized counselling by health care provider patients were again classified for change in various stages of trans theoretical model.

Apart from stages before intervention they were classified into one additional stage of maintenance where people have sustained 
their behaviour change for a while (defined as 4 weeks to 6 months) and intend to maintain the behaviour change going forward. People in this stage work to prevent relapse to earlier stages.

The cessation was defined as self-reported sustained abstinence for 4 weeks to month 6 . The self-reported abstinence at week 1,4, month 3 and month 6 was verified by relatives and attendants over the phone when patient was not present, with questions such as "have they ever seen them smoking", "smelled smoke around them"

Reduction in smoking behaviour was defined when subject reduced number of cigarettes or bidi to half or more than half of their pre-counselling smoked number in a week.

\section{Bias}

Health care professional doing smoking cessation was blinded to smoking history and nicotine dependence. Though he or she was aware of follow up visit and stage of smoking. Follow up and cessation stage could not be blinded because of nature of counselling which was individualized in our case.

\section{Study size}

Prospective study was planned over the period of 1-year recruitment period with 6 months follow up. Our is a tertiary hospital that caters 3 cities and 10 villages where total population is about 1.9 millions [18]. Considering prevalence of smoking in the region from previous study to be $12.4 \%$ [19], sample size calculated was 167 [20].

The variables analysed were: i) the nicotine dependence; ii) the level of literacy; and iii) the smoking status at the various followups (continued or stopped or reduced smoking).

\section{Statistical methods}

After the data was collected, it was subjected to analysis using SPSS statistical software (ver. 20.0 onwards, IBM Corp., USA). Descriptive data is presented as mean $\pm \mathrm{SD}$, median \pm (interquartile range), or as percentages. Comparison between the various groups was done using the Pearson Chi-square test /ANOVA (for categorical variables), unpaired Student's $t$-test or the MannWhitney U-test or Kruskal-Wallis test for continuous variables. The results were considered statistically significant at $p$-value $<0.05$.

Patient who were lost to follow up were not analysed further in follow up visits. To study the effect of counselling services on smoking cessation, at each follow up patients who returned were divided in two groups, one group where they continued smoking and one where they reduced and totally stopped smoking. Mc Nemar Test was used to calculate $p$ value to check significance of each session of counselling. The STROBE guideline was used to guide the report of this prospective study.

\section{Results}

\section{Participants}

In a prospective study conducted in Chest Clinic, 3488 new patients visited outpatient department. Out of these 2564 patients were non-smokers which were directly excluded from study; 924 potentially eligible patients were screened for smoking cessation programme. Those who were willing for further follow up and gave informed consent were enrolled for the study. Total 207 patients were enrolled while 198, 197, 192 returned for further follow ups after 1 week, 1 month and $3^{\text {rd }}$ month respectively. To assess final stage of smoking cessation at 6 months only 172 patients returned.

Of the 35 patients who were lost to follow up, upon telephonic contact it was found that 9 died of which 5 were having lung carcinoma, 3 had COPD and 1 lost his life in road traffic accident. 11 patients told they had stopped smoking but were not analysed. 15 patients could not be traced despite best efforts.

\section{Descriptive data}

In total 207 patients enrolled in study, majority were 202 (97.6\%) males. The mean age of study subjects was $50.74 \pm 14.74$ with maximum patients of age group 45-60 (44.4\%). 133 (64.3\%) were illiterate, $24(11.6 \%)$ had taken education up to primary level, $29(14.0 \%)$ had completed secondary education and $21(10.1 \%)$ were graduates. Majority smoked bidi (177) $85.5 \%$ followed by cigarettes $7.7 \%$, while there were other few $6.2 \%$ who used to smoke both bidi and cigarettes or hukkah. Mean duration of smoking in patients presenting and participating in study was $29.43 \pm 14.72$ years. Mean age of staring smoking patient presenting and participating in study was $21.57 \pm 7.48$ years. $116(56 \%)$ of smokers started smoking in influence of friends i.e. peer pressure followed by imitating father or relatives (Table 1).

Cough $(96.6 \%)$ followed by breathlessness $(92.7 \%)$ were the most common complaints with which patients presented to clinic. Dyspepsia $(21.2 \%)$ and chest pain $(7.7 \%)$ were other common complaints. There were few who presented with hoarseness of voice, haemoptysis, rhinitis and fever. Each one was interviewed to determine the stage of readiness to quit smoking and it was found out $44(21.3 \%)$ were in Pre-contemplation stage, 93 (44.9\%) were in Contemplation stage, $57(27.5 \%)$ were in Preparation stage and $13(6.3 \%)$ were in Action stage according to health belief model.

\section{Outcome data}

The outcome data are summarized in Table 2.

First follow-up (after 1 week): participants after initial evaluation underwent one to one counselling sessions with a healthcare professional. At first follow up after 1 week, 198 returned, $86(41.6 \%)$ continued smoking; 81 patients $(39.1 \%)$ conveyed reduction in smoking number of bidi or cigarettes, while $31(15 \%)$ stopped smoking. Patients who reduced or stopped smoking were more than who continued at first follow up, but this observation was not statistically significant $(\mathrm{p}=0.065)$.

Second follow-up (after 1 month): 197 participants returned for the second follow-up after 1 month, 28 (13.8\%) continued smoking. 95 patients $(45.9 \%)$ conveyed a reduction in the smoking number of bidi or cigarettes, while $73(35.3 \%)$ stopped smoking. Patients who reduced or stopped smoking were more than who continued at second follow up and this was statistically significant $(\mathrm{p}=0.005)$.

Third follow-up (after 3 months): 192 returned for third follow up at three months, $13(6.3 \%)$ continued smoking. 52 patients $(25.1$ $\%$ ) conveyed a reduction in smoking number of bidi or cigarettes, while 127 (61.4\%) stopped smoking. Patients who reduced or 
stopped smoking were more than who continued at third follow up and this was statistically significant $(\mathrm{p}=0.005)$ (Figure 1$)$.

Follow up after 6 months: 172 returned for follow up at six months, $36(17.3 \%)$ continued smoking; 30 patients $(14.5 \%)$ conveyed a reduction in the smoking number of bidi or cigarettes, while $106(51.2 \%)$ stopped smoking. In the next 3 months, 21 patients relapsed but the majority continued abstinence from smoking; $36(17.4 \%)$ were in Action stage according to health belief model, 93 (44.9\%) were in Maintenance stage, 30 (14.5\%) were in Relapse stage and continued smoking.

\section{Main results}

RBICS had significant effect on ones with loss of motivation i.e. pre-contemplators and contemplators. It was successful in shifting $38.6 \%$ of pre-contemplators and $51.6 \%$ of contemplators into maintenance stage of TTM, while $20.5 \%$ of pre-contemplators and $22.5 \%$ of contemplators into action stage.

Stage at presentation was seen in relation with stage after counselling, with maximum number of patients falling under Maintenance stage, with p-value less than 0.05 making it statistically significant. That is RIBCS resulted in significant abstinence, as majority were in maintenance (Table 3) (Figure 1).

Nicotine dependence was significantly related to the stage before and after counselling. Subjects with higher nicotine dependence were more in precontemplation and contemplation stage. Higher nicotine dependence scores were seen in those who relapsed (Table 4).

\section{Other analyses}

The point prevalence excellence rate in follow up-I was $15 \%$, follow up-II was $35.3 \%$ and follow up-III was $61.9 \%$ which was statistically significant. When we take both abstinence and reduction in smoking behaviour the $\mathrm{p}$-value is $<0.05$. The point prevalence of abstinence rate (questionnaire validated) 1 months to 6 months is almost 4 times. The prevalence of abstinence rate at 6 months among smokers in pre-contemplation, contemplation, preparation were $27.4 \%, 51.6 \%, 54.3 \%$ respectively while reduction in smoking behaviour was seen in $41.9 \%, 74.1 \%, 69.8 \%$ respectively which were statistically significant.

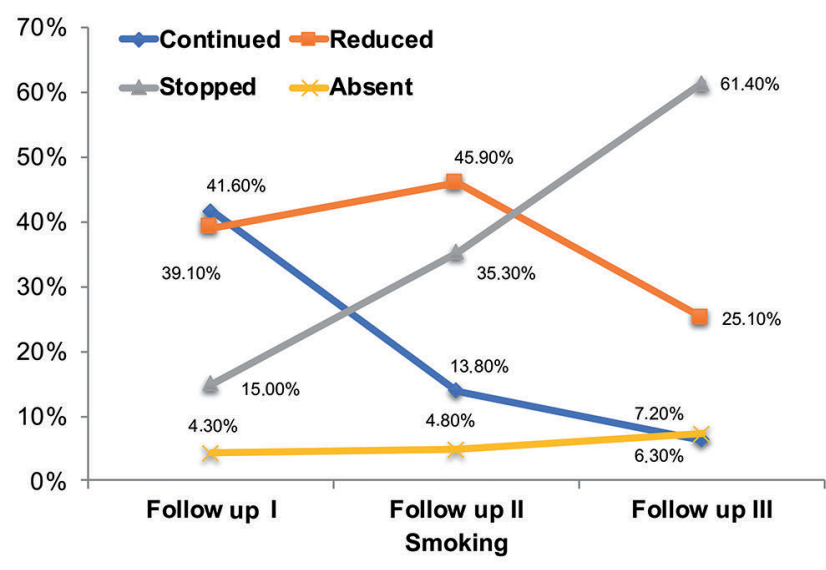

Figure 1. Outcome data for the first, second and third follow-ups.
In the present study, the majority of smokers were uneducated though literacy level was not significantly related with quitting rate and smoking reduction behaviour at the stage after counselling as $\mathrm{p}$-value was $>0.05$ i.e. 0.118 . Thus, indicating the fact literacy levels are no hindrance in reduction of smoking behaviour when repeated counselling is done (Table 5).

Table 1. Socio-demographic characteristics of patients presenting in chest clinic who smoked anytime in last 1 year.

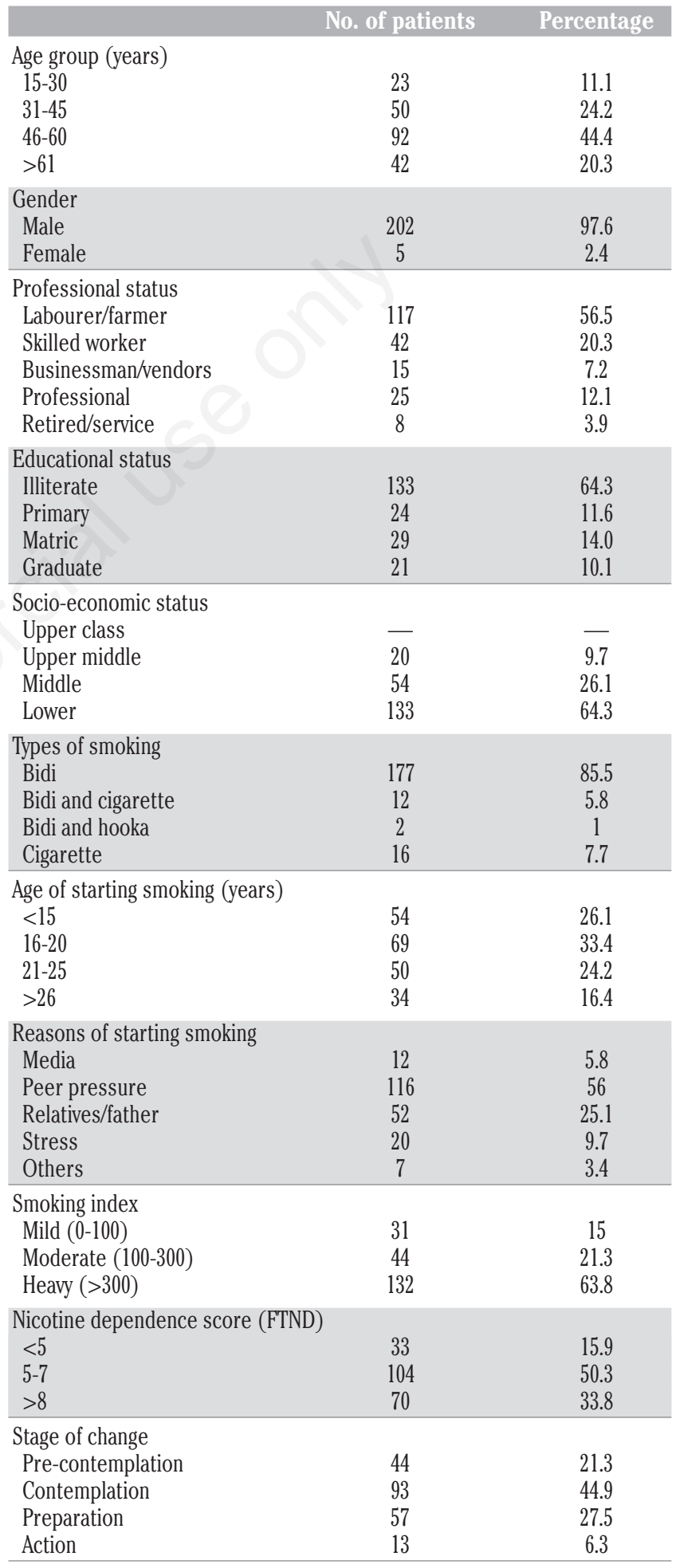




\section{Discussion}

The present study aimed to assess the readiness to quit smoking in patients visiting a tertiary centre's chest clinic. In our study, $97.6 \%$ were males; most of the smokers were bidi users $(85.5 \%)$ which is like our country's data [21]. The mean age of initiation of smoking was $21.57 \pm 7.5$ years with minimum age being 11 years and maximum being 54 years which was similar to study conducted in our country where mean age of initiation of smoking was $18.8 \pm 5.5$ years and $20.8 \pm 8.5$ years for bidi and cigarette smokers respectively [22]. About $73 \%$ of smokers reported high level of nicotine dependence (FTND score $\geq 5 / 10$ ) and mean dependence score was $6.0 \pm 1.96$ which was like the study by Nerin et al. who studied 385 smokers [23].

At presentation, according to TTM, 44 (21.3\%) were in precontemplation, $93(44.9 \%)$ were in contemplation, 57 (27.5\%) were in preparation and $13(6.3 \%)$ were in action stage which is similar

Table 2. Summary of outcomes data.

\begin{tabular}{lcccc} 
Status of smoking & $\begin{array}{c}\text { Follow-up I } \\
\text { (after 1 week) }\end{array}$ & $\begin{array}{c}\text { Follow-up II } \\
\text { (after 1 month) }\end{array}$ & $\begin{array}{c}\text { Follow-up III } \\
\text { (after 3 months) }\end{array}$ & $\begin{array}{c}\text { Follow-up } \\
\text { after } 6 \text { months }\end{array}$ \\
Continued smoking & $86(41.6 \%)$ & $28(13.8 \%)$ & $13(6.3 \%)$ & $36(17.4 \%)$ \\
Reduced smoking & $81(39.1 \%)$ & $95(45.9 \%)$ & $52(25.1 \%)$ & $30(14.5 \%)$ \\
\hline Stopped smoking & $31(15 \%)$ & $73(35.3 \%)$ & $127(61.4 \%)$ & $106(51.2 \%)$ \\
Absent & $9(4.3 \%)$ & $10(4.8 \%)$ & $15(7.2 \%)$ & $35(16 \%)$ \\
\hline p-value & 0.065 & 0.0005 & 0.0005 & 0.005 \\
\hline
\end{tabular}

Table 3. Comparison of stage at presentation with stage after RIBCS.

\begin{tabular}{|c|c|c|c|c|c|}
\hline \multirow{2}{*}{ Stage at Presentation } & \multicolumn{3}{|c|}{ Stage after counselling } & & \multirow[t]{2}{*}{ Total } \\
\hline & Lost & Action & Maintenance & Relapse & \\
\hline Action & 3 & - & 10 & - & 13 \\
\hline Contemplation & 14 & 21 & 48 & 10 & 93 \\
\hline Pre-contemplation & 5 & 9 & 17 & 13 & 44 \\
\hline Preparation & 13 & 6 & 31 & 7 & 57 \\
\hline Total & 35 & 36 & 106 & 30 & 207 \\
\hline p-value & & & 0.013 & & \\
\hline
\end{tabular}

RIBCS, repeated individual behavioural counselling.

Table 4. Nicotine dependence in relation with stage at presentation and after counselling.

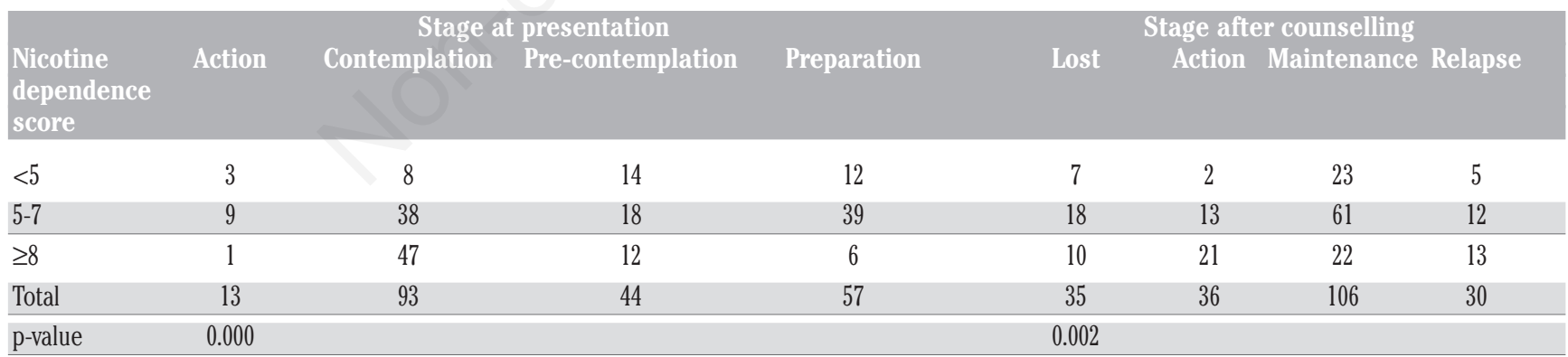

Table 5. Literacy in relation with stage after counselling.

\begin{tabular}{lccccc} 
Stage after counselling & \multicolumn{2}{c}{ literacy } & \multicolumn{2}{c}{ Total } \\
& Illiterate & Primary & Matric & Graduate \\
Lost (\%) & $25(71.4)$ & $3(8)$ & $4(11.4)$ & $3(8)$ & 35 \\
Action (\%) & $18(50)$ & $7(19.4)$ & $6(16.6)$ & $5(13.8)$ & 36 \\
\hline Maintenance (\%) & $75(70.7)$ & $8(7.5)$ & $16(15.1)$ & $7(6.6)$ & 106 \\
Relapse (\%) & $15(50)$ & $6(20)$ & $3(10)$ & $6(20)$ & 30 \\
\hline Total & 133 & 24 & 29 & 21 & 207 \\
p-value & & & 0.118 & & \\
\hline
\end{tabular}


to other data from our country [24], though it was bit different from western data where approximately $40 \%$ of the sample was in Precontemplation, $40 \%$ in Contemplation, and $20 \%$ in Preparation stage [25]. This difference in presentation could be attributed to the fact that participants in our study were patients presenting to a chest clinic who were aware of smoking related nature of their disease. Also, most of the population in our area belong to certain religion i.e. Sikhism which prohibits use of tobacco. As $72.4 \%$ of our participants were thinking of quitting smoking, it highlights the urgent need of comprehensive strategy that would help smokers to quit. At the same time health care professionals should also be encouraged to take smoking cessation seriously, as interventions are less likely to be offered to one with trivial complaints [26]. Hospitals should be encouraged to have smoking cessation clinics along with a regular outpatient departments.

Various drugs like bupropion, varenicline and cytisine have been shown to improve the chances of quitting. Moreover, majority of the studies suggest that benefit after 1 year starts diminishing. Meta-analysis shows effect diminish over period and people relapse [27-28]. Therefore, self-will with change of behaviour is needed for the prolonged cessation. Physician counselling plus pharmacotherapy has appeared to be better than single approach. Physician counselling in the form of 5A's are a backbone of any smoking cessation programme. As a primary clinical physician we can encourage patients in quitting smoking. Even the brief advice of single contact from a general practitioner is extremely worthwhile, as it has been shown that $2 \%$ to $8 \%$ patients quit smoking when counselled by health professional with or without pharmacotherapy [29-30]. It is estimated that if primary care provider advise an additional (apart from normal practice) $50 \%$ of smokers to stop smoking, including the various recommendation like nicotine replacement therapy then it would add an additional 75,000 extra ex-smokers a year nationally, at a cost of under $£ 700$ per life year gained [31].

As our country is a low-income country majority do not have resources or health insurances, that they can spare for non-emergent conditions and de-addiction measures are always last on list. As health professional we are at unique position to motivate as well as help in quitting smoking. We have improvised this logic to provide cost effective modality i.e. using RIBC in all participants after fulfilling inclusion criteria where they were repeatedly counselled along with symptomatic treatment for their complaints and were followed up for 6 months.

\section{Key results}

The prevalence of abstinence rate at 6 months among smokers in Pre-contemplation, Contemplation, Preparation was $27.4 \%$, $51.6 \%, 54.3 \%$ while reduction in smoking behaviour was seen in $41.9 \%, 74.1 \%, 69.8 \%$ which was statistically significant. Nakamura et al. did study in 979 smokers, smokers in intervention group received stage matched individual counselling, point prevalence rate at 6 months was 5 times the control group which was almost like present study [32].

Various factors were analysed which could have been associated with effect on smoking cessation. Repeated counselling had positive effect which was statistically significant on smoking cessation. Stage at presentation was seen in relation with stage after counselling, with maximum number of patients falling under Maintenance stage, with p-value less than 0.05 making it statistically significant. Higher nicotine dependence score were seen in those who relapsed, call for intensive pharmacological therapy in form of nicotine replacement.

\section{Strengths}

The present study had some methodological strengths. First, it was performed in a population recruited from smokers who visited chest clinic. Therefore, the study subjects did not actively volunteer to take part in the smoking intervention and had no special motivation to quit smoking. Second, good adherence with the intervention was also obtained. Therefore, we consider that we could evaluate the effects of repeated individual counselling in an ideal setting. Third, we used an intention-to-treat analysis; as a result, a modest abstinence rate was estimated.

\section{Limitations}

First, the duration of the follow-up was relatively short and limited to the treatment period. Most relapses take place within 5-6 months of cessation. A point prevalence measure taken at 1 year would certainly capture the great majority of those relapse events. Second, self-reports of smoking status were believed and not biochemically validated using expired carbon monoxide (CO). Third, present study smoking cessation program was effective, but moderately intensive. Fourth there were no groups to compare the effect. We did not want to deny anyone of opportunity of counselling as it has been shown to have some effect. Patient catering to our centre were from poor socio-economic status so were not very inclined towards pharmacotherapy.

\section{Conclusions}

This study highlights the point that individualised counselling in clinical setup can be helpful and have greater effect if done repeatedly. Literacy level has no effect on counselling, against common myth. It has been shown illiterates responded better to cessation advice.

Considering its dissemination into health care settings, it will be difficult for health care providers to use it in routine health services such as at an outpatient clinic or health check-up setting, because the time allotted for behavioural counselling in these settings is limited.

From a public health perspective, health care settings have an excellent potential to yield many quitters if effective programs are successively combined into routine health services. It is a need of hour to develop a brief smoking intervention program tailored for use in an outpatient clinic or health check-up setting. Also, a training program needs to be developed for health care providers.

\section{References}

1. Jha P, Jacob B, Gajalakshmi V, et al. A nationally representative case-control study of smoking and death in India. N Engl J Med 2008;358:1137-47.

2. Dwivedi S, Srivastava S, Dwivedi G. Smoking associated with 
malignancy, hypertension, chronic obstructive pulmonary disease and concurrent coronary artery disease: Report of Nine cases. Indian J Chest Dis Allied Sci 2006;48:213.

3. West R, Mcneill A, Raw M. Smoking cessation guidelines for health professionals: an update. Thorax 2000;55:987-99.

4. US Department of Health and Human Services. The health benefits of smoking cessation: A report of the surgeon general. 1990; pp. 618.

5. Goldman L, Bennett JC. Cecil textbook of medicine, 21st ed. Philadelphia, WB Saunders Co.; 2000.

6. Molyneux A, Lewis S, Leivers U, et al. Clinical trial comparing nicotine replacement therapy (NRT) plus brief counselling, brief counselling alone, and minimal intervention on smoking cessation in hospital inpatients. Thorax 2003;58:484-8.

7. Lifrak P, Gariti P, Alterman AI, et al. Results of two levels of adjunctive treatment used with the nicotine patch. Am J Addict 1997;6:93-8

8. Alterman AI, Gariti P, Mulvaney F. Short- and long-term smoking cessation for three levels of intensity of behavioral treatment. Psychol Addict Behav 2001;15:261-4.

9. Nagy K, Barabas K, Nari T. Attitudes of Hungarian health care professional students to tobacco and alcohol. Eur J Dent Educ 2004;4:32-5.

10. Duong M, Rangarajan S, Zhang X, et al. Effects of bidi smoking on all-cause mortality and cardiorespiratory outcomes in men from south Asia: an observational community-based substudy of the Prospective Urban Rural Epidemiology Study (PURE). Lancet Glob Health 2017;5:e168-76.

11. Gatrad R, Gatrad A, Sheikh A. Hookah smoking. BMJ 2007 7:335:20.

12. Pulvers K, Scheuermann TS, Romero DR, et al. Classifying a smoker scale in adult daily and nondaily smokers. Nicotine Tob Res 2014;16:591-9.

13. Jindal SK, Malik SK, Dhand R, et al. Bronchogenic carcinoma in Northern India. Thorax 1982;37:343-7.

14. Fagerstrom KO. Smoking cessation treatment with sustained release bupropion: optimising approach to management. Drugs 2002;60:1-70.

15. Prochaska JO, DiClemente CC. Stages and processes of selfchange of smoking: toward an integrative model of change. J Consult Clin Psychol 1983;51:390-5.

16. Gupta SK. Respiratory disorders among workers in a railway workshop. Ind J Tub 1995;42:161.

17. Cai L, Cui W, You D, et al. Socioeconomic variations in nicotine dependence in rural southwest China. BMC Public Health 2015;15:1158.

18. Government of Punjab, District Patiala. Demography. Accessed on: 28 November 2019. Available from: https://patiala.nic.in/ demography/
19. Mishra S, Joseph RA, Gupta PC, et al. Trends in bidi and cigarette smoking in India from 1998 to 2015, by age, gender and education. BMJ Global Health 2016;1:e000005.

20. Charan J, Biswas T. How to calculate sample size for different study designs in medical research? Indian J Psychol Med 2013;35:121-6.

21. Jindal SK, Aggarwal AN, Chaudhry K, et al. Tobacco smoking in India: prevalence, quit-rates and respiratory morbidity. Indian J Chest Dis Allied Sci 2006;48:37-42.

22. D'Souza G, Rekha DP, Sreedaran P, et al. Clinicoepidemiological profile of tobacco users attending a tobacco cessation clinic in a teaching hospital in Bangalore city. Lung India 2012;29:137-42.

23. Nerín I, Crucelaegui A, Mas A, Guillén D. Profile of smokers who seek treatment at a smoking cessation clinic. Arch Bronconeumol 2003;39:298-302.

24. Velicer WF, Fava JL, Prochaska JO, et al. Distribution of smokers by stage in three representative samples. Prev Med 1995;24:401-11.

25. Goldstein MG, Niaura R, Willey-Lessne C, et al. Physicians counseling smokers. A population-based survey of patients' perceptions of health care provider-delivered smoking cessation interventions. Arch Intern Med 1997;157:1313-9.

26. Wu P, Wilson K, Dimoulas P, Mills EJ. Effectiveness of smoking cessation therapies: a systematic review and metaanalysis. BMC Public Health 2006;6:300.

27. Rosen LJ, Galili T, Kott J, et al Diminishing benefit of smoking cessation medications during the first year: a meta-analysis of randomized controlled trials. Addiction 2018;113:805-16.

28. Cahill K, Stevens S, Perera R, Lancaster T. Pharmacological interventions for smoking cessation: an overview and network meta-analysis. Cochrane Database System Rev 2013; CD009329.

29. Fiore MC, Bailey WC, Cohen SJ, et al. Smoking cessation. Clinical practice guideline No 18, Publication No 96-0692. Rockville; Agency for Health Care Policy and Research, US Department of Health and Human Services; 1996.

30. Silagy C, Ketteridge $\mathrm{S}$. The effectiveness of physician advice to aid smoking cessation. In: Cochrane Library. Oxford: Update Software; 1998

31. Parrott S, Godfrey C, Raw M, et al. Guidance for commissioners on the cost-effectiveness of smoking cessation interventions. Thorax 1998;53:S2-37.

32. Nakamura M, Masui S, Oshima A, et al Effects of stagematched repeated individual counseling on smoking cessation: A randomized controlled trial for the high-risk strategy by lifestyle modification (HISLIM) study. Environ Health Prev Med 2004;9:152-60. 